\title{
Deep Mining of Teaching Data Under Online Teaching Quality Control
}

\author{
Ying Gao \\ Teaching Quality Control and Evaluation Office \\ Yan'an University \\ Yan'an, China
}

\author{
Wendong Wang* \\ Teaching Quality Control and Evaluation Office \\ Yan'an University \\ Yan'an, China \\ *Corresponding Author
}

\begin{abstract}
In response to the national call for "no extension of education, no suspension of classes", online teaching in our school is fully launched as scheduled. In order to ensure the quality of undergraduate online classroom teaching, from the point of view of teaching quality monitoring, through investigation, taking the teaching data of Yan'an University as an example, taking a small part to see the whole, this paper analyzes the existing problems in online teaching in colleges and universities in China at present, and puts forward some improvement methods and suggestions.
\end{abstract}

Keywords—online teaching; platform; teaching data

\section{INTRODUCTION}

In accordance with the guidelines of the Ministry of Education on the organization and management of online teaching in general institutions of higher learning during the period of epidemic prevention and control and the circular of the Shan xi Provincial Education Department on the teaching work in institutions of higher learning during the period of epidemic prevention and control, our school's activities of "no extension of education, no suspension of classes" have been arranged and carefully prepared, and undergraduate teaching has been carried out as scheduled in the form of online courses. Since the beginning of school week, the network teaching operation is smooth. In order to ensure to meet the quality requirements of the Ministry of Education "to ensure that online learning and offline classroom teaching quality is substantially equivalent", online teaching quality monitoring is particularly important. In order to do a good job of online teaching quality control, the evaluation department specially designed two electronic questionnaires of "online teaching listening record sheet" and "online teaching student questionnaire". Through the calculation, analysis and depth mining of 186 online listening record sheets and 20846 student questionnaires, the paper analyzes the essence of the problems behind the data, and then puts forward some suggestions for improvement.

\section{TEACHING DATA MINING}

As an important part of teaching quality monitoring system, teaching supervision plays an irreplaceable role in stabilizing teaching order and improving teaching quality. In order to strengthen the monitoring of online teaching quality and improve the quality of online teaching, supervision is required to enter the online classroom to master the situation of teaching by teachers and students in any class. As the main body of school teaching work, the student group is in the first scene of teaching activities, is the most direct beneficiary and the most profound feeling of teaching quality, and has the most say in the quality of teaching. Their suggestions should be paid more attention by managers to the improvement of teaching and the attitude towards school teaching management. Therefore, the teaching data obtained by the network questionnaire, which is mainly supervised and supplemented by student evaluation, are deeply excavated.

Comparing the results of the first day of school attendance (Fig .1) with the results of the first week of school attendance (Fig .2), the data were found (Fig .1 and 2, The scores were set as follows :9 as excellent , 8 as good ,7 as basic qualified ,6 as qualified and 5 as unqualified), whether it was the teaching design or content of the course, the safety and operation of the platform, and the interaction in classroom teaching, all the indexes had obvious and varying degrees of decline, only the normal operation of the teaching platform did not drop but rose Behavioural compliance scores were highest for each item, while the normal operation of the teaching platform was the lowest for each item. Teachers and students discuss interaction 8.08 and 7.98 points, students attend class 8.1 and 8.02 points these two points are only higher Teaching platform running items 7.92 and 7.96 points, scores between basic qualified and good.

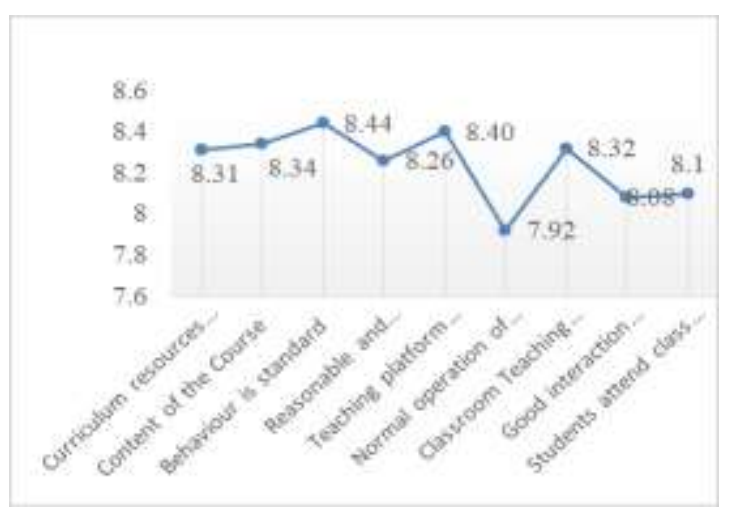

Fig. 1. Effect of the first day of school attendance

Foundation item: 2019 Shaanxi Higher Education Teaching Reform Research Project. The Research and Practice of Teaching Quality Control System of Local Colleges and Universities "Four rings and two wings".

Project Number :19BZ031. 


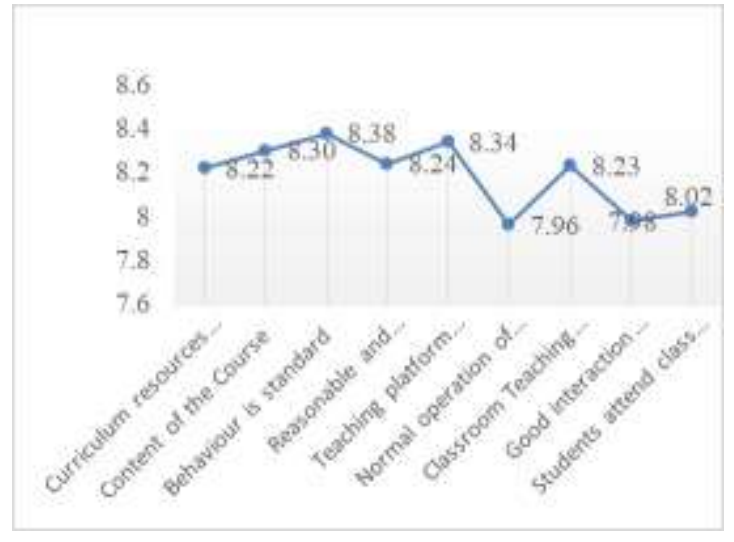

Fig. 2. Effect of supervised attendance one week after school term

\section{A. "Supervision" and "Guide" of Teaching Supervision}

According to a graph (Fig. 3), 80.85\% of the supervisors have communicated with the teachers after class. Only $19.15 \%$ of the supervisors did not provide after-school feedback and guidance. However, according to the data in figures 1 and 2, the "supervisor" and "guide" of undergraduate online teaching are not effectively linked, that is to say, supervision does not play a "supervisory" role in the guidance of teachers or the improvement of teaching management service level. Supervision should not only play the role of teaching supervision, but also play the role of teaching guidance Function. Supervision and guidance are equally important, emphasis on supervision and supervision, there will be a lot of management work, work results are not ideal. Emphasis on guidance and supervision of the collection of data will be inaccurate, affecting the analysis of teaching state data, failed to better improve the teaching work for teachers to play a scientific role.

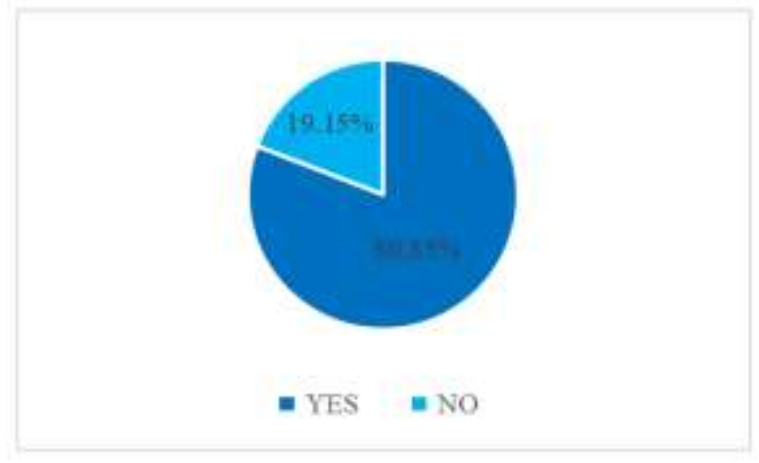

Fig. 3. Post-school feedback chart

\section{B. Evaluation and Service in Teaching Monitoring System}

According to the data of 20,846 questionnaires on students' learning in online teaching (Fig .4), most of the teachers and students can adapt to the new teaching mode quickly $98.5 \%$ of the students expressed their understanding and support for the online teaching in the school. While $1.08 \%$ of the unsatisfactory and $0.42 \%$ of the very unsatisfactory data sources are mainly due to the centralized class stage, the network teaching platform appeared in the situation of inaccessible, offline, Catton and so on. Figure 1 and figure 2 show that the teaching platform is functioning well, up $4 \%$ from 7.92 to 7.96 . The only trend among the ten indicators is not to decline but to rise. Comprehensive study and judgment, it is concluded that the biggest problem of online teaching, teachers and students pay the most attention to the difficulties in the data network and teaching platform.

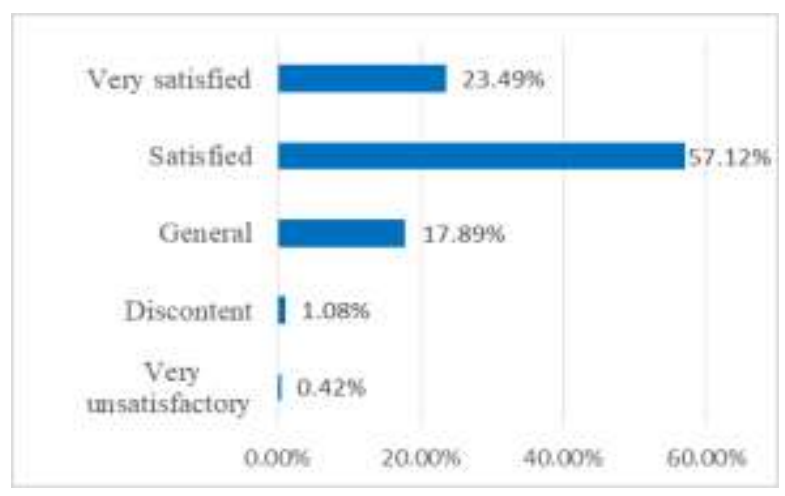

Fig. 4. Students evaluate the effect of online teaching in a week

Through the data analysis of the teaching method and the teaching platform diagram (Fig. 5), we can see that the online teaching form of colleges and universities is not rigid, "recording and broadcasting live voice", the platform is also used in a variety of ways, "conference group virtual classroom". Among them, the use rate of "school online" was the highest, reaching $40.74 \%$, while the use rate of "wisdom tree online classroom" was the lowest, which was only $14.82 \% .40 .46 \%$ of the use of the school recommended external platform, such as Tencent classroom, Tencent conference, WeChat group, QQ group live classroom and so on. And in terms of teaching implementation, the most courses use not only one in classroom teaching A platform. According to the actual situation, teachers make flexible use of the advantages of multiple platforms to carry out teaching, it can also be said that most teachers to ensure the quality of the classroom, at least A, B two sets of teaching programs, with teachers gradually skilled in the use of online platforms, they have begun to actively explore new teaching models.

At present reflects the better and stable class software, there are Tencent classroom, Tencent conference, qq live classroom, school online and so on.

\section{C. "Teaching" and "Quality" in Teaching Monitoring System}

Through the students online teaching learning situation network questionnaire survey, online teaching students actively participate in interaction reasons such as Fig. 5, we can see that online teaching content, teachers' teaching and guidance, whether for active reasons — interested in classroom content, or for passive reasons _ linked to results, most students are willing to actively participate in the classroom guidance, only $1.93 \%$ of other reasons cause students unwilling to participate in classroom interaction. The most desirable form of classroom interaction is shown in Fig. 6, It is clear that $64.39 \%$ of the students want to participate in the discussion in the classroom, and the teacher can actively guide the students to think $60.84 \%$ 
of the students hope that the teacher can solve the problems or puzzles in the classroom in time; $46.99 \%$ hope that the teacher can give timely feedback and explanation of the homework in the classroom. In figures 1 and 2, the reasons are analyzed for the low scores of teacher-student discussion items and student attendance items. In classroom teaching, the vast majority of students are willing to participate in classroom interaction and discussion, while the low score indicates that the teacher's teaching method can not meet the increasing students' willingness to learn, or is not the learning method that students are willing to accept. $64.99 \%$ of the students hope that after returning to school, the teachers will be able to explain the key and difficult points again (Fig. 7), plus the data of students' participation and attendance, we can see that online teaching is still not satisfactory for the grasp of the important and difficult knowledge.

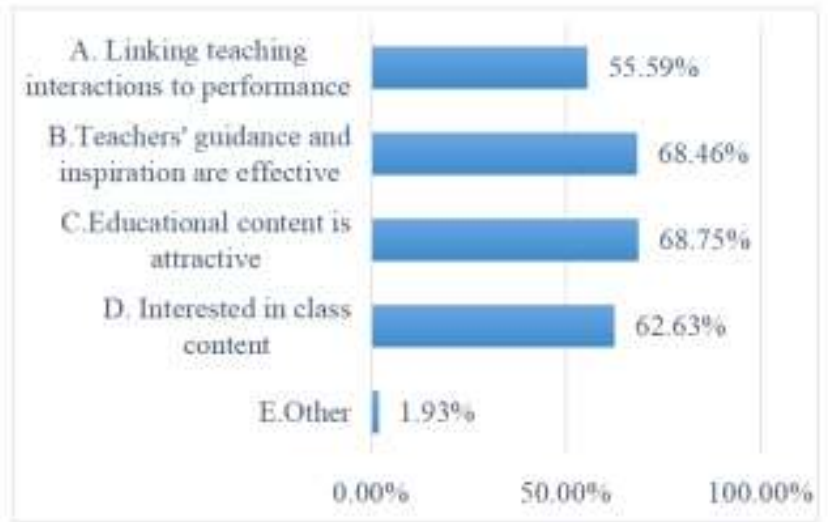

Fig. 5. The reasons why online teaching students actively participate in interaction

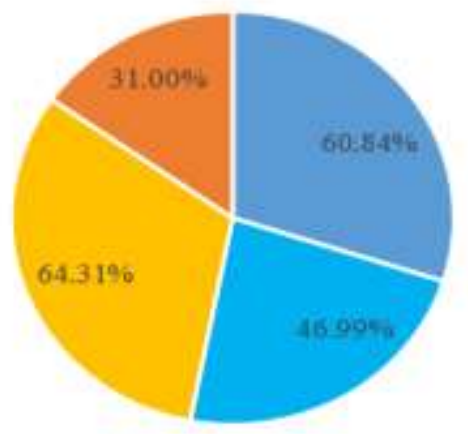

Solve my problems in time

Timely feedback on operations

To participate in the discussion and lead me to think positively

= To supervise my learning status

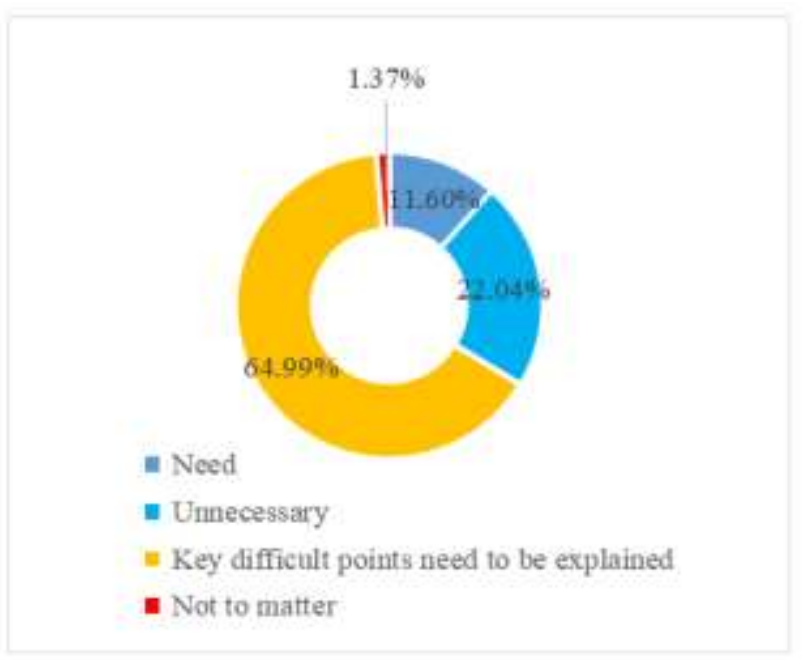

Fig. 7. Need for teachers to repeat the course after returning to school

\section{IMPROVEMENTS AND RECOMMENDATIONS}

1. Supervision work is the key work in the teaching quality monitoring system. It is suggested that "supervisor" and "guide" should be closely combined, and the problems found by "supervisor" should be established to form a long-term "help" and "guide" record, adhere to "guide" in place, and ensure that "supervision" has traces, results and promotion.

2. Carry on "multi-platform multi-way multi-method" hybrid teaching reform. When the platform is selected, consider the class can be live, interactive, after-class playback, effectively solve the situation that individual students miss the key points because of the network is not good; platform mix, using the university students video resources library of famous teacher resources to organize students to preview, improve learning efficiency, formal consideration of the use of new technologies, such as screen separation technology, new media to use their advantages use; teaching methods do not stick to the traditional classroom teaching questions. We should use the concept of "independent cooperative inquiry" and actively carry out the reform of teaching methods, such as "project orientation", "action orientation", "case teaching", "taskdriven", "cooperative learning", "problem teaching", "situational teaching", "integration of theory and practice", "heuristic" and "discussion".

3. In the face of "Internet Aboriginal" college students, as a group of teachers of "Internet Immigrants", we should actively explore, learn and use digital resources to be a "host" rather than a "student" in the classroom. Distribution of preview materials before class, such as making electronic version of teaching materials or photos to give the focus, encourage students to learn independently. In class, teachers actively guide and discuss, use a variety of new media to interact with students, arouse enthusiasm, increase interest, increase participation, and improve the teaching effect. After class to evaluate and guide the learning effect, and give feedback.

Fig. 6. The most desirable forms of classroom interaction 


\section{CONCLUSION}

Through the analysis of the online teaching data of Yan'an University, this paper finds that the supervision work of learning management in our country is not ideal, and the teaching quality in the teaching monitoring system is still a difficult problem; and the corresponding improvement methods and suggestions are given.

\section{REFERENCES}

[1] Chen Weidong. Future Classroom Studies from the Perspective of Educational Technology [D].Shanghai: East China Normal University ,2012.(In Chinese).

[2] Yang Lijun, Han Xiaoling. A Study on Learning Effectiveness Evaluation Tool for Chinese and American College Students Higher Education Development and Assessment ,2013(2). (In Chinese).

[3] Wang Huifang. Study on Construction of Quality Control and Guarantee System for MOOC Courses [J].] Contemporary Educational Practice and Teaching Research ,2018(9):7-8.(In Chinese).

[4] Shaanxi Provincial Department of Education issued: Ankang College multi-measures to ensure network teaching work _ institutions of higher learning,2020.(In Chinese). 